Research Article

\title{
GROWTH AND PERSISTENCE OF COMMON TEMPERATURE PASTURE SPECIES UNDER LOW LIGHT AND LOW R:FR RATIO
}

\author{
N. R. Devkota \\ Institute of Agriculture and Animal Sciences, Rampur, Chitwan \\ Email:dnaba@wlink.com.np
}

\begin{abstract}
The effects of varied PAR and R:FR ratio on tillering and shoot dry weight production of temperate pasture species were evaluated at Massey University New Zealand using split-plot design with four blocks. The main plots were $\%$ transmitted PAR (photosynthetically active radiation; mmoles photons $\mathrm{m}^{-2} \mathrm{~s}^{-1}, 400$ $700 \mathrm{~nm}$ ) and R:FR ratios (red to far red ratios) with $2 \times 2$ factors of PAR and R: FR, i.e. medium (38 and $39 \%$ ) and low (16 and 17\%) PAR-each with two natural (1.33 and 1.34) and two reduced (0.57 each) R:FR ratios. The treatment combination was such that each low and medium PAR level had a natural and a reduced R:FR ratio. PAR levels with natural R: FR ratio were imposed by differing densities of neutral shade cloth (Sarlon) with a layer of clear filter, while low R:FR ratio was created with the use of a blue filter. Nine pasture cultivars of seven pasture species: Dactylis glomerata L., Grasslands Wana (cocksfoot); Dactylis glomerata L., PG 74 (cocksfoot); Dactylis glomerata L., PG 321 (cocksfoot); Lolium perenne L. (perennial ryegrass); Holcus lanatus L. (Yorkshire fog); Agrostis capillaris (browntop); Poa trivialis; Trifolium repens L. (white clover), and Lotus uliginosus (lotus) were grown in pots as subplots with four replicate blocks. Six plants were maintained per pot. Plants were harvested at 61 days after imposing shade. There was no effect of R:FR ratio $(\mathrm{P}>0.05)$ on the shoot dry weight per plant, however, significant differences $(\mathrm{P}<0.05)$ for $\mathrm{PAR}$, species, and interaction of PAR, species for shoot dry weight was observed. At low PAR, Lolium perenne, Dactylis glomerata (Wana) and Holcus lanatus had the highest and similar yields, whereas the yield of white clover and lotus were similar and less than for all the grass species. Effects of PAR as well as R:FR were significant $(\mathrm{P}<0.001)$ for total tillers per plant in the shade. Poa trivialis, Agrostis capillaris and Lolium perenne had the highest number of tillers/plant at the low PAR and low R:FR, but did not contribute to higher shoot dry weight at the low PAR, mainly due to their low weight per tiller. Likewise, SLA was significantly $(\mathrm{P}<0.01)$ increased by low PAR but not by low R:FR. Lotus produced a higher $(\mathrm{P}<0.001)$ number of branches at the low PAR than white clover. Comparatively better performance of cocksfoot, especially at low PAR, was mainly due to the ability to produce higher leaf area, higher SLA, and more tillers per plant. The results are discussed in terms of the effects of PAR and R:FR on the yield and yield components with respect to the attributes of shade tolerant pasture species.
\end{abstract}

Key words: PAR, R:FR ratio, wana cocksfoot, nui perennial ryegrass, shade

\section{INTRODUCTION}

The growth, development and productivity of plants are dependent on both quantity and quality of light (Kasperbauer and Hunt, 1998), reduction in which may cause morphological changes in plants. Besides quantity light, the colour of light received by a growing plant also influences where and how the photosynthate is used, known as photomorphogenic function of light. For example, red (R) and far-red (FR) are absorbed by and act through a photoreversible regulatory pigment system of phytochrome. Owing to the presence of the phytochrome pigment system, plants are sensitive to the ratio of the red and far-red quanta that influence the plant development (Lee et al., 1994; Smith, 1994). Generally, under a dense canopy, not only the amount of light received by plant decreases, but the R:FR ratio also decreases because of selective absorption of red light relative to far-red and diffusion of different wavelengths by green tissue (Wan and Sosebee, 1998; Smith 1994). It is hypothesised that the morphological responses of pastoral plants are less affected by low R:RF under a low level of PAR than a high level of PAR, since survival could be more important for a plant at a low level of PAR, and hence the efficiency of utilization of light energy is more important (Corré, 1983) than the quality of light. Tillering/ branching is affected more by shade due to both low photosynthetically-active radiation (PAR) and low R:FR 
than by neutral shade (low PAR and high R:FR) (Wan and Sosebee, 1998). Hence, this study was undertaken.

\section{MATERIALS AND METHODS}

\section{Experimental design}

The experiment was conducted for 122 days for the legumes (10 June to 9 October, 1997), and 112 days (20 June-9 October, 1997) for the grasses at the Plant Growth Unit (PGU), Massey University. Different sowing times for legumes and grass were intended to adjust for differences in germination period. A split-plot design was used with four blocks. The main plots were $\%$ transmitted PAR (photosynthetically active radiation) and R;FR ratios (red to far red ratios) with $2 \times 2$ factors of PAR and R: FR, i.e. medium and low PAR-each with natural and reduced R:FR ratios. Nine pasture species were grown as sub-plots.

PAR levels with natural R:FR ratio were imposed by differing densities of neutral shade cloth (Sarlon) with a layer of clear filter (Effects filters, 30 clear) while low R: FR ratio was created with the use of steel blue filters (Effects filter, 117 steel blue, Chris James and Co. LTD; Lighting Filters, 43 Colville Road, Acton, London W38BL). Shade cloths and filters were supported together on hollow metal frames $(.25 \times 0.84 \times 0.45 \mathrm{~m})$ arranged on benches that were $0.9 \mathrm{~m}$ above the ground. The shade frames were aligned in a north-south direction (across the sun direction) in order to avoid direct radiation during low sun elevation thus enclosed the pots leaving $1 / 3^{\text {rd }}$ portion of the bottom of the pots. It was done to facilitate aeration and to reduce temperature increase due to the use of filters. In the East west direction, the frames completely enclosed the pots. Thus, in each cage of main plot, pots of nine species were accommodated where each pot was only for one species with six plants per pot. Six plants per pot for 3.9 litre size was optimum in terms of spacing, and also for ease of handling as determined on the basis of knowledge of previous experiments of similar kinds. Details of the pasture species and cultivars used are given in Table 1.

Table 1. Pasture species and cultivars used in the experiments

\begin{tabular}{|llll|}
\hline \multicolumn{4}{|c|}{ Pasture species } \\
\hline SN & English name & Scientific name and & Cultivar \\
\hline 1 & White clover & (Trifolium repens L.) & cv. Grasslands Tahora \\
2 & Lotus & (Lotus uliginosus) & cv. Grasslands Mak \\
3 & Cocksfoot & (Dactylis glomerata L.) & cv. Grasslands Wana, (tetraloid) \\
4 & Cocksfoot & (Dactylis glomerata L.), & PG 74, subsp. Izcoi (diploid) \\
5 & Cocksfoot & (Dactylis glomerata L.), & PG 321 subsp. Izcoi (tetraploid) \\
6 & Perennial ryegrass & (Lolium perenne L.) & cv. Grasslands Nui \\
7 & Yorkshire fog & (Holcus lanatus L.) & cv. Massey Basyn \\
8 & Browntop & (Agrostis capillaris) & cv. Grasslands Muster \\
9 & Poa trivialis & (Poa trivialis) & cv. Sabre \\
\hline
\end{tabular}

Seeds of the pasture species were sown on 10 June for legumes, and 20 June, 1997 for grasses in PB 61/2 (3.9 litre) black polypots filled with potting mix $(80 \%$ tree bark $+20 \%$ pumice). Dolomite $300 \mathrm{~g}$, agricultural lime 300g, iron sulphate 50g, and Osmocote plus (16N-3.5P-10.8K) $400 \mathrm{~g}$ per 100 litre were blended with the potting mix, which was rated for medium to long-term $(<9$ months) greenhouse crops. Six plants were maintained per pot. Plants were watered daily.

The pots within cages were re-randomized weekly. Seeds of legumes were inoculated with the appropriate rhizobia. The glasshouse temperature was maintained at $25^{\circ} \mathrm{C}$ until seeds of all plants were fully germinated. Thereafter, day temperature was $15-17^{\circ} \mathrm{C}$, while night temperature was $8-10^{\circ} \mathrm{C}$.

Plants were at first grown in a glasshouse under full available sunlight (Plant Growth Unit, Massey University), and were then transferred to the shade frames on 10 August 1997. All the fully expanded lamina was clipped before imposing shade treatments to avoid confounding effects of full sunlight. Clipped leaves were later oven dried at $70^{\circ} \mathrm{C}$ for 24 hours and weighed and added to the cumulative biomass. Leaves were not clipped once plants were under the shade, and plants were harvested only at the end of experiment. 


\section{Light measurements}

Transmitted PAR (mmoles $\mathrm{m}^{-2} \mathrm{~s}^{-1}, 400-700 \mathrm{~nm}$ ) was measured daily from 1200 to $1300 \mathrm{~h}$ throughout the experiment on each main plot just above the pasture plants with a portable quantum sensor (LI-COR, Inc., Model LI-185). R: FR ratios (ratio of photon irradiance between 655 and $665 \mathrm{~nm} /$ between 725 and $735 \mathrm{~nm}$ ) (Smith, 1994) were measured with Skye sensor during clear sky days for three times, thus were the mean of three measurements.

On the basis of measurements, 38 and 39\% PAR levels were determined under medium PAR, each having 181 mmoles $\mathrm{m}^{-2} \mathrm{~s}^{-1}$ with natural R:FR of 1.33-1.34, and 189 mmoles $\mathrm{m}^{-2} \mathrm{~s}^{-1}$ with low R:RF of 0.57 , respectively. Likewise 16 and $17 \%$ PAR levels under low PAR, each having 78 mmoles $\mathrm{m}^{-2} \mathrm{~s}^{-1}$ with natural R:FR of 1.32-1.37, and 84 mmoles $\mathrm{m}^{-2} \mathrm{~s}^{-1}$ with low R: RF of 0.57 were also determined, respectively. Thus the transmitted PAR was $38,39,17$, and $16 \%$ of the ambient PAR under full sunlight each with R:FR ratio of $1.33-1.34,0.57,1.32-$ 1.37 , and 0.57 , respectively.

\section{Morphological measurements}

Plants were harvested on 9 October, 1997 (61 days after imposing shade). One plant was randomly selected in each pot and all the leaves, stems, mature and immature leaves were separated. Leaf area was measured, then leaves and stems dried at $70^{\circ} \mathrm{C}$ for 24 hours to calculate cumulative biomass per plant. Number of tillers was also determined for the same plant. The remaining five plants were clipped to the media surface. Shoots were dried at $70^{\circ} \mathrm{C}$ for 24 hours, weighed, and added to the above ground shoot mass at the final harvest. Chlorophyll concentration was measured once in September.

\section{Statistical analysis}

PROC GLM programme of SAS version 6.12 (SAS, 1997) was used for all analyses. Residuals were examined for their normality, and appropriate transformation was carried out when needed. Treatment means were compared using orthogonal contrasts. For all the tables SEM denotes standard error of means; NS, nonsignificant at $\mathrm{P}>0.05$.

\section{RESULTS}

\section{Shoot dry weight}

There was no effect of R: FR ratio $(\mathrm{P}>0.05)$ on the shoot dry weight per plant of the pasture species studied. The interaction of PAR $\times$ R:FR, species $\times$ R:FR, and species $\times$ PAR $\times$ R:FR were also not significant $(\mathrm{P}>0.05)$. However, there were significant $(\mathrm{P}<0.05)$ effects of $\mathrm{PAR}$, species, and PAR $\times$ species on the shoot dry weight (Table 2).

Higher shoot dry weight was produced by all the species at medium PAR than at low PAR. At medium PAR, perennial ryegrass and Yorkshire fog had the highest shoot dry weight followed by Wana cocksfoot and browntop. Shoot dry weights of white clover and lotus were similar and lower than all the grass species (Table 2). At low PAR, perennial ryegrass and Wana cocksfoot were similar and had the highest shoot dry weight, whereas shoot dry weight of white clover and lotus was similar and less than all the grass species. Perennial ryegrass and Yorkshire fog had 45 and 39\% shoot dry weight, respectively, of their medium PAR shoot dry weight at low PAR, compared with 59\% for Wana cocksfoot (Table 2).

Table 2. Effect of level of PAR and R:FR ratio on shoot dry weight ( $\mathrm{g} / \mathrm{plant}$ ) of hill grass species and other species at final harvest in glasshouse conditions, 1997

\begin{tabular}{|lcccc|}
\hline Species & \multicolumn{4}{c|}{ Percent transmitted PAR and R:FR ratio } \\
\cline { 2 - 5 } & \multicolumn{3}{c|}{ Medium PAR } & \multicolumn{2}{c|}{ Low PAR } \\
\cline { 2 - 5 } & $\mathbf{3 8 \%}$ PAR, Natural R:FR & $\mathbf{3 9 \%}$ PAR, Low R:FR & 16\% PAR, Natural R:FR & 17\% PAR, Low R:FR \\
& $(\mathbf{1 . 3 3 - 1 . 3 4 )}$ & $\mathbf{( 0 . 5 7 )}$ & $\mathbf{( 1 . 3 2 - 1 . 3 7 )}$ & $\mathbf{( 0 . 5 7 )}$ \\
\hline White clover & 1.4 & 1.0 & 0.4 & 0.3 \\
Lotus & 1.0 & 1.1 & 0.4 & 0.4 \\
Cocksfoot (Wana) & 1.9 & 1.8 & 1.2 & 1.0 \\
Cocksfoot (PG 74) & 1.6 & 1.2 & 0.8 & 0.5 \\
\hline
\end{tabular}


Table 2. Cont.......

\begin{tabular}{|c|c|c|c|c|}
\hline Cocksfoot (PG 321) & 1.8 & 1.7 & 0.7 & 0.7 \\
\hline Perennial ryegrass (Nui) & 2.8 & 2.7 & 1.2 & 1.1 \\
\hline Yorkshire fog & 2.7 & 2.8 & 1.3 & 0.9 \\
\hline Browntop & 1.9 & 1.8 & 0.6 & 0.8 \\
\hline Poa trivialis & 1.9 & 1.7 & 0.9 & 1.0 \\
\hline Analysis of variance & probability & SEM & Contrast & \\
\hline $\operatorname{PAR}(\mathrm{A})($ d.f. $=1)$ & $\mathrm{P}<0.001$ & 0.03 & Legumes VS rest & $\mathrm{P}<0.0001$ \\
\hline R:FR (B) (d.f.=1) & NS & 0.03 & Rye vs PG 74, PG 321, wana & $\mathrm{P}<0.0001$ \\
\hline$(A * B)($ d.f. $=1)$ & NS & 0.04 & Rye vs PG 74, PG 321, wana & $\mathrm{P}<0.0001$ \\
\hline Species $(C)$ (d.f. $=8)$ & $\mathrm{P}<0.0001$ & 0.06 & Y. fog, poa, browntop & \\
\hline$\left(C^{*} \mathrm{~A}\right)($ d.f. $=8)$ & $\mathrm{P}<0.0001$ & 0.09 & & \\
\hline
\end{tabular}

\section{Leaf area}

Only the effects of PAR and species significantly affected $(\mathrm{P}<0.05)$ leaf area development. There was no effect ( $P>0.05$ ) of R:FR or any interactions on leaf area per plant (Table 3). Leaf area per plant increased with increased PAR in all pasture species. Yorkshire fog had the highest leaf area in medium as well as in low PAR. Leaf area of Wana cocksfoot was higher than that of perennial ryegrass and legumes. Legume leaf area was the lowest among all the species studied (Table 3).

Table 3. Effect of level PAR, and R:FR ratio on leaf area ( $\left.\mathrm{mm}^{2} / \mathrm{plant}\right)$ of hill grass species and other species at final harvest in glasshouse condition, 1997

\begin{tabular}{|c|c|c|c|c|}
\hline \multirow[t]{3}{*}{ Species } & \multicolumn{4}{|c|}{ Percent transmitted PAR and R:FR ratio } \\
\hline & \multicolumn{2}{|c|}{ Medium PAR } & \multicolumn{2}{|c|}{ Low PAR } \\
\hline & $\begin{array}{c}38 \% \text { PAR , Natural R:FR } \\
(1.33-1.34)\end{array}$ & $\begin{array}{c}39 \% \text { PAR, Low R:FR } \\
(0.57)\end{array}$ & $\begin{array}{c}16 \% \text { PAR, Natural R:FR } \\
(1.32-1.37)\end{array}$ & $\begin{array}{c}17 \% \text { PAR , Low R:FR } \\
(0.57)\end{array}$ \\
\hline White clover & 24656 & 25729 & 10033 & 13496 \\
\hline Lotus & 25085 & 31384 & 12197 & 8953 \\
\hline Cocksfoot (Wana) & 40279 & 34445 & 28152 & 27759 \\
\hline Cocksfoot (PG 74) & 35948 & 27139 & 19450 & 11428 \\
\hline Cocksfoot (PG 321) & 41193 & 33015 & 24203 & 23905 \\
\hline Perennial ryegrass (Nui) & 33237 & 28614 & 23634 & 26921 \\
\hline Yorkshire fog & 75664 & 66468 & 51596 & 47853 \\
\hline Browntop & 29882 & 21729 & 15229 & 15335 \\
\hline Poa trivialis & 27671 & 15199 & 15840 & 14023 \\
\hline Analysis of variance & probability & SEM & Contrasts & \\
\hline PAR (A) (d.f. = 1) & $\mathrm{P}<0.001$ & 1231 & Legumes VS rest & $\mathrm{P}<0.0001$ \\
\hline R:FR (B) (d.f.=1) & NS & 1231 & Wc vs lotus & NS \\
\hline \multirow[t]{2}{*}{ Species (C) (d.f. $=8)$} & $\mathrm{P}<0.0001$ & 2428 & Rye vs PG 74, PG 321, wana, & \\
\hline & & & Y.fog, Poa, browntop & NS \\
\hline
\end{tabular}

\section{Total tillers}

Effects of PAR, R:FR, and species were significant $(\mathrm{P}<0.001)$ to total tillers/plant. There were, however, no significant $(\mathrm{P}>0.05)$ interactive effects of PAR, R:FR, and species for total tillers per plant (Table 4).

Higher numbers of total tillers or branches per plant were produced by all the species at the medium PAR than at the low PAR. The highest numbers of tillers were on the Poa and browntop among the grasses, while lotus had more branches per plant than white clover in the case of legumes. This trend was similar under low PAR (Table 4). Tiller numbers of Wana cocksfoot, PG 74 cocksfoot and PG 321 cocksfoot were smaller than 
for perennial ryegrass, but were not significantly different $(\mathrm{P}>0.05)$. In general, lower number of tillers were produced by all species under low R:FR compared with natural R: FR except in the case of browntop (Table 4).

Table 4. Effect of PAR, and R:FR ratio on loge total tillers or stolons/ branches per plant of hill grass species and other species at final harvest in glasshouse condition, 1997

\begin{tabular}{|c|c|c|c|c|}
\hline \multirow[t]{3}{*}{ Species } & \multicolumn{4}{|c|}{ Percent transmitted PAR and R:FR ratio } \\
\hline & \multicolumn{2}{|c|}{ Medium PAR } & \multicolumn{2}{|c|}{ Low PAR } \\
\hline & $\begin{array}{c}38 \% \text { PAR , Natural R:FR } \\
(1.33-1.34)\end{array}$ & $\begin{array}{c}39 \% \text { PAR, Low R:FR } \\
(0.57)\end{array}$ & $\begin{array}{c}16 \% \text { PAR , Natural R:FR } \\
(1.32-1.37)\end{array}$ & $\begin{array}{c}17 \% \text { PAR, Low R:FR } \\
(0.57)\end{array}$ \\
\hline White clover & $2.97(19.4)$ & $2.65(14.1)$ & $2.21(9.1)$ & $1.73(5.6)$ \\
\hline Lotus & $3.79(44.2)$ & $3.61(36.9)$ & $3.39(29.6)$ & $3.19(24.2)$ \\
\hline Cocksfoot (Wana) & $3.00(20.0)$ & $2.95(19.1)$ & $2.62(13.7)$ & $2.22(9.2)$ \\
\hline Cocksfoot (PG 74) & $2.82(16.7)$ & $2.56(12.9)$ & $1.97(7.1)$ & $1.73(5.6)$ \\
\hline Cocksfoot (PG 321) & $2.78(16.1)$ & $2.62(13.7)$ & $2.18(8.8)$ & $2.31(10.0)$ \\
\hline Perennial ryegrass (Nui) & $3.28(26.5)$ & $3.29(26.8)$ & $2.97(19.4)$ & $2.67(14.4)$ \\
\hline Yorkshire fog & $3.27(26.3)$ & $3.09(21.9)$ & $2.86(17.4)$ & $2.76(15.7)$ \\
\hline Browntop & $3.52(33.7)$ & $3.67(39.2)$ & $3.13(22.8)$ & $3.24(25.5)$ \\
\hline Poa trivialis & $4.03(56.2)$ & $3.78(43.8)$ & $3.55(34.8)$ & $3.47(32.1)$ \\
\hline Analysis of variance & probability & SEM & Contrasts & \\
\hline $\operatorname{PAR}(\mathrm{A})($ d.f. $=1)$ & $\mathrm{P}<0.0001$ & 0.01 & We vs lotus & $\mathrm{P}<0.0001$ \\
\hline R:FR (B) (d.f.=1) & $\mathrm{P}<0.001$ & & Rye vs PG 74, PG 321, Wana & $\mathrm{P}<0.0001$ \\
\hline$(A * B)($ d.f. $=1)$ & NS & 0.04 & & \\
\hline Species (C) (d.f. $=8)$ & $\mathrm{P}<0.0001$ & 0.06 & & \\
\hline
\end{tabular}

Values in parentheses are back transformed

\section{Specific leaf area (SLA)}

PAR significantly affected SLA $(\mathrm{P}<0.01)$, but there was no effect of R: FR on SLA, and also the interaction between PAR and R:FR was not significant $(\mathrm{P}>0.05)$. There was a significant effect of species on SLA, and also a significant interaction of species $¥ \mathrm{R}: \mathrm{FR}(\mathrm{P}<0.01)$ (Table 5).

All the species had a higher SLA under low PAR than under medium PAR, but the species like browntop, Poa and Yorkshire fog had similar SLA at both PAR levels. At low PAR, lotus had the highest SLA, whereas the Poa had the lowest. SLA of Wana cocksfoot was higher than perennial ryegrass at both PAR levels (Table 5). R: FR had no effect on SLA. Yorkshire fog had the highest SLA followed by PG 74 cocksfoot and Wana cocksfoot among the grass species, while lotus had a higher SLA than white clover. SLA of perennial ryegrass and Poa were the lowest among the species under both natural and low R: FR (Table 5).

\section{Chlorophyll concentration}

Browntop, Poa, white clover, and Wana cocksfoot had significantly higher concentrations of chlorophyll 'a' than other species, and perennial ryegrass had the least chlorophyll 'a' concentration. Except for lotus, PG 74 cocksfoot, and PG 321 cocksfoot, all species had higher chlorophyll concentrations at medium PAR than at the low PAR. Concentration for chlorophyll 'b' were similar to those for chlorophyll 'a' but all the species had lower concentrations of chlorophyll ' $\mathrm{b}$ ' at medium PAR than at the low PAR, except perennial ryegrass and browntop. The ratio of chlorophyll 'a'/'b' was higher at reduced R: FR than at natural R: FR for all species except Poa, which had a similar ratio at both PAR levels (data not presented). 
Table 5. Effect of PAR and R:FR ratio on specific leaf area $\left(\mathrm{mm}^{2} / \mathrm{mg}\right)$ of hill grass species and other species at the final harvest in a glasshouse, 1997

\begin{tabular}{|c|c|c|c|c|}
\hline \multirow[t]{3}{*}{ Species } & \multicolumn{4}{|c|}{ Percent transmitted PAR and R:FR ratio } \\
\hline & \multicolumn{2}{|c|}{ Medium PAR } & \multicolumn{2}{|c|}{ Low PAR } \\
\hline & $\begin{array}{c}38 \% \text { PAR , Natural R:FR } \\
(1.33)\end{array}$ & $\begin{array}{c}39 \% \text { PAR, Low R:FR } \\
(0.57)\end{array}$ & $\begin{array}{c}16 \% \text { PAR , Natural R:FR } \\
(1.34)\end{array}$ & $\begin{array}{c}17 \% \text { PAR , Low R:FR } \\
(0.57)\end{array}$ \\
\hline White clover & 43.2 & 46.8 & 38.4 & 60.0 \\
\hline Lotus & 43.6 & 49.5 & 59.7 & 53.6 \\
\hline Cocksfoot (Wana) & 26.3 & 25.7 & 32.6 & 36.8 \\
\hline Cocksfoot (PG 74) & 33.7 & 31.6 & 37.2 & 39.0 \\
\hline Cocksfoot (PG 321) & 29.4 & 24.9 & 29.0 & 32.0 \\
\hline Perennial ryegrass (Nui) & 16.0 & 16.1 & 23.7 & 22.1 \\
\hline Yorkshire fog & 41.0 & 39.6 & 47.2 & 48.1 \\
\hline Browntop & 23.3 & 23.4 & 27.4 & 24.4 \\
\hline Poa trivialis & 22.8 & 18.7 & 22.1 & 20.3 \\
\hline Analysis of variance & probability & SEM & Contrast & \\
\hline $\operatorname{PAR}(\mathrm{A})($ d.f. $=1)$ & $\mathrm{P}<0.01$ & 0.85 & Legumes VS rest & $\mathrm{P}<0.0001$ \\
\hline R:FR (B) (d.f.=1) & NS & 0.85 & Wc vs lotus & $\mathrm{P}<0.05$ \\
\hline$(A * B)($ d.f. $=1)$ & NS & 0.95 & Rye vs PG 74, PG 321, wana, & $\mathrm{P}<0.001$ \\
\hline Species (C) (d.f. $=8)$ & $\mathrm{P}<0.001$ & 1.43 & Rye vs PG 74, PG 321, wana, & \\
\hline$(\mathrm{C} * \mathrm{~B})(\mathrm{d} . \mathrm{f} .=8)$ & $\mathrm{P}<0.01$ & 2.03 & Y.fog, Poa, browntop & $\mathrm{P}<0.001$ \\
\hline$(C * A * B)($ d.f. $=8)$ & $\mathrm{P}<0.05$ & 2.87 & & \\
\hline
\end{tabular}

Comparatively, tiller related information was least affected at low PAR and also at reduced R: FR. At low PAR, $>80 \%$ of the total tillers was produced by the pasture species to that of medium PAR, while it was $>95 \%$ in the case of low R: FR relative to that of natural R :FR (Table 6). However, there was a significant effect of R: FR on the tillering ability of pasture species studied (Table 4). Significant effects of R: FR to the pasture species also suggests that there could be a different response of light quality as per differences in species. For example Casal et al. (1986) reported that tillering was reduced in ryegrass at low R: FR. Different in species in terms of responses of R:FR ratio to the tillering in this study, partly could also due to general application of reduced R:FR inside the shade frame rather than treating specifically to the individual plant parts. Hay et al. (1997) reported the localised response of R:FR to the apical bud of white clover in order to get the effects of reduced R:FR treatment.

Table 6. Summary table of the parameters measured: mean values of the PAR and R:FR and the differences

\begin{tabular}{|c|c|c|c|c|c|c|}
\hline \multirow[t]{2}{*}{ Parameters } & \multicolumn{3}{|c|}{ PAR } & \multicolumn{3}{|c|}{$\mathrm{R}: \mathrm{FR}$} \\
\hline & $\begin{array}{c}\text { Mean of medium } \\
\operatorname{PAR}(38,39 \%) \\
\text { (a) }\end{array}$ & $\begin{array}{l}\text { Mean of low } \\
\operatorname{PAR}(16,17 \%) \\
\text { (b) }\end{array}$ & $\begin{array}{c}\text { Ratio of } \\
\text { relativity index } \\
(\%)^{* *}\end{array}$ & $\begin{array}{c}\text { Mean of natural } \\
\text { R:FR } \\
(38,16 \% \text { PAR) (a) }\end{array}$ & $\begin{array}{c}\text { Mean of low } \\
\text { R:FR } \\
(39,17 \% \text { PAR) (b) }\end{array}$ & $\begin{array}{c}\text { Ratio of relativity } \\
\text { index } \\
(\%)^{* *}\end{array}$ \\
\hline Dry weight (g/plant) & 1.86 & 0.78 & 41 & 1.40 & 1.29 & 92 \\
\hline Leaf area $\left(\mathrm{mm}^{2} /\right.$ plant $)$ & 34296 & 21666 & 63 & 29663 & 15206 & 51 \\
\hline Specific leaf area $\left(\mathrm{mm}^{2} / \mathrm{mg}\right)$ & 30 & 36 & 117 & 33 & 34 & 102 \\
\hline Log total tillers / plant & 3.20 & 2.67 & 83 & 3.01 & 2.86 & 95 \\
\hline
\end{tabular}

** value of low (b)/value of medium (a) *100

\section{DISCUSSIONS}

\section{Pasture species under medium and low PAR and natural/reduced R:FR}

The results showed that there was no interaction between PAR and R:FR for all the parameters measured. There were no interactive effects of R: FR $\times$ species, and PAR $\times$ R: FR $\times$ species for any parameters except SLA. The effect of R: FR was not significant for most of the parameters studied, except tillerings. 
Effects of R: FR on plant species, perhaps important from physiological points of view (Keating and Carberry, 1993) to understand the effects of increased or decreased ratio of R:FR light on a particular plant part such as the growing point of white clover, and the shoot base of grasses (Hay et al.,1997), but results of this study clearly indicated that PAR is more important to the pasture species than R: FR ratio from the production point of view. This also showed that the ability of plant species to tolerate low light (shading) has its basis in photosynthesis, viz. in the efficiency of utilization of light energy (Corré 1983). The role of photomorphogenic light is mainly to work as a regulator of photosynthate allocation in growing plants (Kasperbauer and Hunt, 1998). To survive, plants first need to be able to photosynthise. The quantity of light is therefore more critical and more important for the plant under low light (Corré, 1983) than the quality of light. Allocation of biomass to plant organs can be considered as a strategy to improve the surviving ability under varied environmental conditions. For example, an increase in leaves suggests a greater capacity for energy capture and carbon fixation, whereas an increase in roots suggests an increased ability of the plant to absorb water and nutrients (Lee et al., 1994). In this experiment, shade (low PAR, as well as low R:FR) treatments affected allocation to the leaves, which were heavier at medium PAR, natural R: FR, and lighter at reduced PAR and R: FR ratio. However, there was no significant effect $(\mathrm{P}>0.05)$ of $\mathrm{R}$ : FR on leaf area development, indicating the lower impact of light quality than quantity. However, these conclusions are limited by the fact that they relate to only two levels of PAR and R:FR ratios. This prevented that a lower R:FR ratio than were measured in this experiment would have had a greater effect on the parameters measured.

In general, responses to low-light stress include increase in plant leaf area (Sanderson et al., 1997) which is thought to be at the expense of leaf thickness (Kephart and Buxton, 1993) resulting in the increments of SLA. Research results showed that European tall-shrub species increased SLA in shade (Grubb et al., 1996), and the pasture species like white clover grown at the reduced light of $30 \mathrm{~J} \mathrm{~m}^{-2} \mathrm{~s}^{-1}$ had also greater SLA and longer petiols than unshaded (Dennis and Woledge, 1983). Dennis and Woledge (1983) demonstrated that white clover grown in dim light or shade had a higher SLA which is interpreted as an adaptation to shade in that for each unit weight of leaf dry matter, a greater area is exposed to the available light. Higher SLA therefore means greater ability of pastures to adapt and produce more in shade. Devkota et al. (1997) reported that lotus, Yorkshire fog, and Wana cocksfoot all produced higher SLA and also the shoot dry weight at heavy shade (14\% transmitted PAR). Higher SLA of Wana cocksfoot, Lotus, PG 74 cocksfoot and Yorkshire fog than of perennial ryegrass at low PAR could be positively associated with higher shoot dry weight. Higher SLA of Wana cocksfoot, Lotus, and Yorkshire fog than of perennial ryegrass at low PAR could be positively associated with higher shoot dry weight

Wana cocksfoot was one of the best species in terms of shoot dry weight per plant, mainly due to the larger leaf area per plant, higher number of tillers and SLA per plant. This is consistent with the results of the previous studies of similar kinds (Devkota et al., 1997; 1998) that Wana is a shade tolerant species and that it persists well under shade.

Perennial ryegrass also had a greater shoot dry weight per plant like Wana cocksfoot, which was in contrast to the results of the previous studies (Devkota et al., 1997;1998). As in the case of Wana cocksfoot, greater shoot dry weight of perennial ryegrass was mainly supported by the higher leaf area per plant, and higher number of tillers per plant, but not by the SLA. Perennial ryegrass had a lower SLA compared with Wana cocksfoot and Yorkshire fog.

One important reason for the greater shoot dry weight per plant of perennial ryegrass could be the establishment of pasture species under full sunlight at the beginning of the experiment. Similarly, pasture species were not defoliated for the entire experimental period. It is well proved that perennial ryegrass establishes faster than other species even under shade (Barker and Hunt, 1997), and thus could have the advantage of capturing higher resources due to the maintenance of higher tiller numbers and leaf area per plant compared with other species. Nevertheless, this suggests that, provided the optimum leaf area and tiller density are maintained by optimum grazing/defoliation management, perennial ryegrass could be a useful improved grass species to grow under shade despite being a shade intolerance species.

Browntop and Poa produced high shoot dry weight per plant at the medium PAR, but not at the low PAR. Higher shoot dry weight per plant of these species at medium PAR was supported by the higher number of tillers/plant, and chlorophyll concentration (data not presented) rather than leaf area and specific leaf area. 
Shoot dry weight production of both browntop, and Poa was reported worse under dense shade and periodic defoliation (Devkota et al., 1997).

Productive performance was poorer of legumes than grass species at both shade level. However, lotus was less affected than white clover under low PAR in terms of shoot dry weight per plant. Lotus had higher leaf area than white clover at medium PAR, but was lower than white clover at low PAR (data not presented). The relatively poor performance of white clover appeared to result from the sensitivity of the stolons to low light. Pasture species such as Wana cocksfoot was in better position in terms of greater leaf area production under the low PAR, and were least affected by the changes in light quality. Effects of R: FR ratio on the tillering of species considered in this study could not make negative impacts as they had higher shoot dry weight per plant than other species under low PAR. The abilities of plants to regenerate leaf area to maximise interception of available radiation, and to utilise photosynthate for tillering and stolon development could be the critical factors that determine production and persistence of pasture species (Chen, 1993) under low irradiance.

\section{REFERENCES CITED}

Barker, S. W. and J. A. Hunt. 1997. Effects of shade by stands on grass species and cultivar selection for football pitches. Intl. Turfgrass Soc. Res. J. 8:593-601.

Casal, J. J., R. A Sanchez, and V. A. Deregibus. 1986. The effect of plant density on tillering: the involvement of R/FR ratio and the proportion of radiation intercepted per plant. J. Exptl. Bot. 26:365-371.

Chen, C. P. 1993. Pastures as the secondary component in tree-pasture systems. In: M.J. Barker (Ed.), Grasslands for Our World, pp.756-762. SIR Publishing, Wellington, New Zealand.

Corré, W.J. 1983. Growth and morphogenesis of sun and shade plants II. The influence of light quality. Acta Bot. Neerl. 32 (3):185-202.

Dennis, W.D. and J. Woledge. 1983. The effect of shade during leaf expansion on photosynthesis by white clover leaves. Ann. Bot. 51:111-118.

Devkota, N. R., P. D. Kemp, and J. Hodgson. 1997. Screening pasture species for shade tolerance. Proc. Agron. Soc. New Zealand 27:119-128.

Devkota, N. R., P. D. Kemp., I. Valentine, and J. Hodgson. 1998. Performance of perennial ryegrass and cocksfoot cultivars under tree shade. Proc. Agron. Soc. New Zealand 28:129-135.

Grubb, P. J., W.G. Lee., J. Kollmann, and J. B. Wilson. 1996. Interaction of irradiance and soil nutrient supply on growth of seedlings of ten European tall-shrub species and Fagus sylvatica. J. Ecol. 84:827-840.

Hay, M. J. M., Ch. Robin., P.C.D. Newton., A. Cresswell, and J. Tilbrook. 1997. Effects of lowered light quality (R:FR ratio) at targeted organs on branching of Trifolium repens. Proc. 18th Intl. Grasslands Cong., Canada. ID NO. 1092.

Kasperbauer, M.J. and P. G. Hunt. 1998. Far-red light affects photosynthate allocation and yield of tomato over red mulch. Crop Sci. 38:970-974.

Keating, B.A and P.S. Carberry. 1993. Resource capture and use in intercropping: Solar radiation. Field Crop Res. 34:273-301.

Kephart, K. D. and D. R. Buxton. 1993. Forage quality responses of $\mathrm{C}_{3}$ and $\mathrm{C}_{4}$ perennial grasses to shade. Crop Sci. 33:831-837.

Lee, W.W., S.F. Oberbauer., B. Krishnapillay., M. Marzalina., M. Haris, and S.K.Yap. 1994. Forest shade and seedling development in fine dipterocarps. Proceedings, Fifth round-table conference on Dipterocarps, Chiang Mai, Thailand, 7-10 November, 1994. Forest Research Institute Malaysia (FRIM), Kualalumpur. pp. 102-116.

Sanderson, M. A., D.W. Stair, and M.A. Hussey. 1997. Physiological and morhological responses of perennial forages to stress. Adv. Agron. 59:171-224.

SAS Institute Inc. 1997. SAS User's guide: Statistics, Version 6.12, SAS Inc., Cary, North Carolina, USA.

Smith, H. 1994. Sensing the light environment: the functions of the phytochrome family. In: R.E. Kendrick and G.H.M. Kronenberg (eds.). Photomorphogenesis in Plants ( $2^{\text {nd }}$ ed). Kendrick, Kluwer, Dordrecht. pp. 377-416.

Wan, C. and R.E. Sosebee. 1998. Tillering responses to red: far-red light ratio during different phenological stages in Eragrotis curvula. Env.Expt. Bot. 40: 247-254. 